\title{
ДИСкУССИИ
}

DOI: https://doi.org/10.15688/jvolsu2.2016.4.25

UDC 81'22

Submitted: 14.09.2016

LBC 81.002

Accepted: 18.10 .2016

\section{LINGUA-SEMIOTIC CREATIVITY \\ IN THE DISCURSIVE SPACE OF SCIENCE FICTION: PROLEGOMENA TO DEFINITION}

\author{
Andrey V. Olyanich \\ Volgograd State Agrarian University, Volgograd, Russian Federation \\ Lyubov M. Rylshchikova \\ Volgograd State Agrarian University, Volgograd, Russian Federation
}

\begin{abstract}
The article defines the concept of the ontological status of creativity, based on the creativity phenomena in general and linguistic creativity in particular. We investigate the role of lingua-semiotic creativity in science fiction discourse formation; allocate linguistic creative units as the basic units of science fiction discourse. Lingua-semiotic creativity is defined as a basic constitutive feature of science fiction discourse. Lingua-semiotic creativity is represented as the ability to handle images and put these images always as new signs, i.e. "to invent a new reality", then immersing them in the hyperreal (fantastic) discourse, the new communicative environment. It is an innovative use of existing and the invention of new linguistic forms of communication in innovation (unreal) or imaginary environment, it's an ability of the creative person (writer and narrator) to create linguistic signs of fantastic reality (hyperreality of the future), giving them functionally loaded definition and shape to their actualization special communicative environment (art works of science-fiction theme). This cognitive category is reflected as person's ability to mentally master the material reality, to discover in it the objects and phenomena that need to be improved, or to predict the creation of new objects / phenomena that meet the growing needs of man, then to semiotize imagination objects / phenomena, realizing their images in verbal and non-verbal signs.
\end{abstract}

Key words: discourse, sign, concept, creativity, linguistic creative unit, lingua-semiotics, need.

\section{ЛИНГВОСЕМИОТИЧЕСКАЯ КРЕАТИВНОСТЬ В ДИСКУРСИВНОМ ПРОСТРАНСТВЕ НАУЧНОЙ ФАНТАСТИКИ: ПРОЛЕГОМЕНЫ К ОПРЕДЕЛЕНИЮ}

\author{
Андрей Владимирович Олянич \\ Волгоградский государственный аграрный университет, г. Волгоград, Российская Федерация \\ Любовь Михайловна Рыльщикова \\ Волгоградский государственный аграрный университет, г. Волгоград, Российская Федерация
}


Аннотация. В статье авторы определяют онтологический статус понятия лингвосемиотической креативности, исходя из феноменов креативности в целом и лингвистической креативности в частности. Исследуется роль лингвосемиотической креативности в научно-фантастическом дискурсоразвертывании; выделяется лингвокреатема как базовая единица научно-фантастического дискурса. Лингвосемиотическая креативность денотируется как базовый конститутивный признак научно-фантастического дискурса. Она репрезентирована как способность оперировать образами и воплощать эти образы всегда в новые знаки, то есть «изобретать новую реальность», погружая их затем в гиперреальный (фантастический) дискурс, в новое коммуникативное окружение. Она представляет собой инновационное использование имеющихся и изобретение новых языковых форм для коммуникации в инновационной (нереальной) или воображаемой среде, является способностью творческой персоны (писателя и рассказчика) создавать языковые знаки фантастической реальности (гиперреальности будущего), давать им функционально нагруженные определения и формировать для их актуализации особую коммуникативную среду (художественные произведения научнофантастической тематики). Это когнитивная категория, поскольку рефлектирует способность человека ментально освоить материальную действительность, обнаружить в ней объекты и феномены, нуждающиеся в усовершенствовании, или прогнозировать создание новых объектов / феноменов, отвечающих растущим потребностям человека, чтобы затем семиотизировать воображенные объекты / феномены, воплотив их образы в вербальные и невербальные знаки.

Ключевые слова: дискурс, знак, концепт, креативность, лингвокреатема, лингвосемиотика, потребность.

1

Человек постоянно использует свои ментальные, когнитивные и языковые возможности при освоении материального мира, одновременно стремясь заглянуть в свое будущее как можно дальше и рисуя себе иные миры. Среди нас живут те, кому креативность присуща онтологически, как свойство, позволяющее представить эти миры максимально четко, привлекая к процессу воображения собственный рациональный - сегодняшний или вчерашний - опыт. Это писатели-фантасты, которые формируют особый язык и особый дискурс - научно-фантастический.

Научно-фантастический дискурс есть не что иное, как «особый тип художественно-литературного дискурса, доминирующая черта которого - репрезентация фантастической реальности в целях адекватной передачи этоса, логоса и пафоса литературной личности для воплощения ее идеалов и ценностей в причудливых и неожиданных формах “возможных миров” с целью художественного воздействия на читателя. В рамках данного типа дискурса моделируется “возможный мир в квадрате” (статус художественного вымысла умножается на статус фантастического вымысла): если художественная реальность - это уже “возможный мир”, то в художественной фантастической реальности аспекты языка как орудия риторического конструирования картины мира, вариативной интерпретации действи- тельности значительно усиливают свое действие» [12, с. 297].

Формулируя понятие научно-фантастического дискурса, С.Г. Иняшкин полагает, что «научно-фантастический дискурс может рассматриваться как уникальное дискурсивное образование пророческого характера, претерпевшее значительные изменения под влиянием социально-политических событий и научных достижений второй половины XX столетия. <..> Научно-фантастический дискурс представляет собой совокупность реализованных в научно-фантастических произведениях высказываний на тему будущего, согласующихся с определенными правилами их построения и имеющих своей целью развлечение, размышление, моделирование, предостережение, побуждение к развитию той или иной научной сферы» [8, с. 118].

Несомненна связь научно-фантастического дискурса с потребностями: известно, что человеческие нужды имеют тенденцию к возвышению и понижению. Однако чаще всего, что и показывает сегодняшняя реальность, потребности - главным образом витальные демонстрируют склонность к росту, усложнению и трансформации [11]. Их удовлетворение требует поиска новых средств и инструментов, что влечет за собой необходимость в информированности о будущей возможности такого удовлетворения. Таким образом рождаются прогноз и информация о будущем как когнио-ментальные сущности - как концепты. 
В сознании человека как вида возникают образы будущего, способного дать ему то, чего у него нет в наличии в данный момент, но нехватка этих сущностей им уже ощущается.

\section{2}

Эти образы (концепты) опираются на текущую информацию о возможностях изменения реальности до гиперреальности будущего информацию, которая эксплицирована лингвосемиотически, при помощи вербальных и невербальных знаков. В случае, когда существующие знаки реальности не конгруэнтны образу грядущей потребности, человек «включает» когнитивные механизмы номинации и в своем воображении создает новый семиотический конгломерат, актуализируемый в дискурсе фикции, - то есть в научно-фантастическом дискурсе, опираясь на категорию лингвосемиотической креативности.

Данная категория находится в ряду других типов и видов креативности: последняя предполагает проявление когнитивных (в том числе и психологических) способностей человека к творчеству, к ментальному переосмыслению реальности и созданию чего-то нового, ранее не имевшего места в материальной действительности или духовно-социальном пространстве общества. Лингвосемиотическая креативность представляется одним из видов языковой (лингвистической) креативности феномена, который уже неоднократно оказывался в сфере изучения исследователей филологического, психологического и педагогического научных направлений. Однако, как отмечает В.В. Фещенко, «только в последнее время лингвокреативность приобретает статус оперативного термина и ключевой метаязыковой единицы лингвистического анализа. Становится возможным определить понятие творчества... вполне рациональным научным языком филологических наук» $[15$, с. 92$]$.

Рассуждая об основах творчества как процесса, Л.Т. Касперова справедливо замечает, что он синтетичен: «надличностное, объективированное, то есть вечное, и индивидуализированное, личное, сливаются, и происходит реализация творчества в произведении. Одним из процессов самопознания субъектом внутренних психических актов и состояний является рефлексия (лат. reflexio обращение назад, самоанализ). Предчувствие начала рождения новой творческой мысли происходит с погружения автора в особое состояние отрешения от реальности, когда окружающий мир практически не воспринимается» [9, с. 134].

В своей работе «Семиотика творчества и лингвистика креативности» В.В. Фещенко констатирует: «Если в психологических и философских исследованиях творческая деятельность является весьма давним объектом изучения, то в семиотическом ключе данная проблема, насколько мне известно, до сих пор не ставилась. В свою очередь, и семиотику на всем протяжении ее развития практически не интересовала проблема знакотворчества, то есть знака со стороны его порождения (хотя отдельные прецеденты можно найти еще в работах В. Волошинова, Л. Выготского, Г. Шпета и Я. Мукаржовского)» $[14$, с. 143]. Таким образом, в статье исследователь характеризует два плана проблемы творчества: 1) творчество как концепт, рассмотренный с семиотических позиций (семиотика творчества); 2) творчество как принцип работы с языковым материалом (лингвистика креативности).

Лингвистическая креативность изучалась как психологический феномен, как способность человека игнорировать стереотипные способы мышления, как высший мыслительный процесс создания нетривиальных языковых моделей (см.: [18]). Эта точка зрения совпадает с воззрениями таких ученых-психологов, как С.А. Медник [20], Ф. Баррон, Д. Харрингтон [19] и др. Выдающийся психолог Дж. Гилфорд определил лингвистическую креативность как «дивергентное языковое мышление» и выделил четыре основных параметра креативности:

1) оригинальность - способность устанавливать отдаленные ассоциации, оригинальные ответы;

2) семантическую гибкость - способность определить главное свойство объекта и предположить новый вариант его использования;

3) образную адаптивную гибкость - способность видоизменить стимул с целью выявить в нем новые свойства и возможности для использования; 
4) семантическую спонтанную гибкость - способность генерировать разнообразные идеи в ситуации нерегламентированности [5, с. 14].

Наиболее существенными для коммуникации В.В. Дементьев считает такие признаки, как интерпретативная деятельность адресата, неконвенциональность, ситуативная обусловленность, лингвистическая креативность [6, с. 33].

Основным свойством лингвистической креативности языковой личности М.А. Холодная называет метафоричность как умение действовать в «невозможном», фантастическом контексте, как предрасположенность к использованию символических, ассоциативных средств при выражении своих мыслей [16]. А.В. Галкина рассматривает лингвистическую креативность как «способность личности к использованию оригинальных, нестандартных лингвистических приемов и средств выражения мысли» $[4$, с. 160]. По мнению Е.Е. Щербаковой и Е.В. Левичевой, лингвистическая креативность «реализуется на каждом уровне языковой личности посредством определенных коммуникативных стратегий. На первом уровне, вербально-семантическом, лингвистическая креативность представляет собой готовность использовать языковые средства для общения. На втором, тезаурусном, уровне лингвистическая креативность проявляется в готовности выбирать стилистические приемы, дефиниции, афоризмы, пословицы в соответствии с мировоззрением личности. Третий, мотивационный, уровень демонстрирует прагматическую функцию лингвистической креативности. Это выражается в способности говорящего осознанно варьировать языковое высказывание в соответствии с поставленной коммуникативной задачей» $[17$, c. 99].

Как полагает Т.В. Тюленева, лингвистическая креативность представляет собой «комплекс способностей к созданию объективно и субъективно новых идеальных продуктов с помощью средств языка, продуцированию устных и письменных высказываний на основе дивергентного мышления, сопряженный со стремлением к творческой речевой деятельности; он характеризуется легкостью (скоростью) продуцирования идей и их вопло- щением в речевой форме, гибкостью (вариативностью) вербального мышления, нестандартностью вербального мышления, способностью к переносу знаний, умений для конструирования новых высказываний, к установлению ассоциативных связей между лексическими единицами, к доработке оригинального речевого продукта для успешной экстериоризации замысла» [13, с. 55].

В.Б. Базилевич определяет лингвистическую креативность как «систему знаний о языке, благодаря которой носитель языка создает новые слова, трансформирует уже существующие языковые средства с целью расширения их семантики, привлечения внимания, достижения определенного эффекта» $[1$, c. 21]. Исследователь, вслед за Т.А. Гридиной, полагает, что «формой лингвокреативной деятельности, связанной с преднамеренным нарушением языковых и речевых норм и направленной на выполнение определенной функции, является языковая игра» $[1$, с. 21$]$.

С мнением В.Б. Базилевич совпадает понимание лингвистической креативности, представленное в работах Е.С. Бутаковой, которая под лингвистической креативностью понимает «способность носителя языка манипулировать знаниями о языке для создания новых слов, модификации уже существующих слов и выражений с целью расширения их семантики, привлечения внимания, создания комического эффекта и пр. Иными словами, лингвистическая креативность представляет собой совокупность знаний о языке и нетривиальный подход носителя языка к их использованию» [2, с. 146].

В качестве формы лингвистической креативности исследователи называют и фразеологическую креативность. Так, И.В. Зыкова выводит определение данного феномена из понятия макрометафорической модели: «Каждая макрометафорическая концептуальная модель в своем формировании проходит следующие этапы: из элементарных концептуальных составляющих образуются сначала более сложные концептуальные неметафорические структуры, затем - все более сложные метафорические структуры, и в итоге - целостная модель. <...> Именно в силу своей сложной организации, основанной на объединении некоего множества взаимосвязанных концеп- 
туальных образований, включая главным образом различные метафорические концепты (или метафорические проекции), макрометафорическая концептуальная модель обладает креативным потенциалом, благодаря которому она способна не только системно продуцировать образы (и, соответственно, семантику) фразеологизмов, но и обусловливать их функционирование в дискурсе, позволяя модифицировать базовые формы образов фразеологических знаков (английских и русских фразеологизмов в частности), тем самым адаптируя их к процессу построения определенного дискурса. Таким образом, исходя из полученных в исследовании результатов, нами было разработано следующее определение фразеологической креативности. С позиции дискурсивного подхода фразеологическая креативность представляет собой способность макрометафорических концептуальных моделей, реализуемую индивидуальным сознанием (или индивидуальной личностью), к коммуникативной адаптации образов фразеологизмов к прагматическим задачам построения определенного дискурса» [7, с. 160].

Некоторые исследователи, признавая за лингвистической креативностью статус категории, считают возможным выделить ее функциональные единицы. Г.А. Копнина и А.П. Сковородников подобной единицей предлагают считать лингвокреатему: «Центральным в стилистике креатива является понятие креатемы. Креатемой называют преднамеренно отобранные или преобразованные средства языка, а также новообразования, нацеленные на создание эстетического впечатления. Однако поскольку понятие креатемы приложимо к творческой продукции любой сферы деятельности, предлагаем уточняющий термин «лингвокреатема» для обозначения языковых / речевых единиц, рождающихся в результате творческой речевой деятельности. Лингвокреатемой может выступать слово, словосочетание, предложение, фрагмент текста (прежде всего сложное синтаксическое целое)» $[10$, с. 101].

Из приведенного краткого обзора следует, что лингвистическая креативность, так или иначе, связана с проявлением когнитивных и творческих возможностей человека в использовании языка для своих прагматических це- лей и имеет дело, как правило, исключительно с языковыми феноменами и языковыми знаками. Лингвосемиотическая креативность также связана с возможностью человека оперировать языковыми знаками, однако ее базовым отличием от креативности лингвистической является то, что она, в первую очередь, характеризует способность человека оперировать ментальными сущностями (концептами), и в том числе знаками неязыковыми. Если лингвистическая креативность есть способность создания языковых феноменов из готового языкового материала (языковая игра, метафоричность, тропеичность, фразеологичность, паремиологические инновации, сленг, жаргон и т. п.), то креативность лингвосемиотическая - это способность оперировать образами и воплощать эти образы всегда в новые знаки, то есть «изобретать новую реальность», погружая их затем в гиперреальный (фантастический) дискурс, в новое коммуникативное окружение.

Иными словами, если креативность лингвистическая есть своеобразная модификация языковых форм для речевой (дискурсивной) фиксации существующей материальной и иной действительности, то креативность лингвосемиотическая представляет собой инновационное использование имеющихся и изобретение новых языковых форм для коммуникации в инновационной (нереальной) или воображаемой среде.

Лингвосемиотическая креативность, по нашему мнению, представляет собой способность творческой персоны (писателя и рассказчика) создавать языковые знаки фантастической реальности (гиперреальности будущего), давать им функционально нагруженные определения и формировать для их актуализации особую коммуникативную среду (художественные произведения научно-фантастической тематики).

Как пишет Е.Н. Галичкина, лингвосемиотическая креативность - это «творческий, культурно обусловленный процесс создания нетривиальных текстов, оказывающих воздействие на реципиентов своей структурой, семантическим содержанием, своеобразием знакового кодирования смысла, образным и когнитивным (образовательным) потенциалом. Лингвосемиотическая креативность как 
коммуникативная категория присуща любому типу общения. < .. > Понятие лингвосемиотической креативности неразрывно связано с категорией языковой личности, поскольку именно ее активная деятельность способствует созданию нетривиального общения и появлению нетривиальной дискурсивной (текстовой) продукции» [3, с. 13].

Лингвосемиотическая креативность это также и когнитивная категория, представляющая собой способность любого человека творчески и ментально освоить материальную действительность, при этом обнаружив в ней объекты и феномены, нуждающиеся в усовершенствовании, или прогнозировать создание новых объектов / феноменов, отвечающих растущим потребностям человека, чтобы затем семиотизировать воображенные объекты / феномены, воплотив их образы в вербальные и невербальные знаки.

\section{3}

Таким образом, основания, по которым лингвосемиотическая креативность представляется нам базовым признаком научно-фантастического дискурса, следующие: специфическая дискурсивная дихотомия «агент - клиент», в которой обязательно присутствие креативного агента, создающего нетривиальные знаки и вбрасывающего в коммуникативную среду новые концепты (писатель-фантаст), и наличие специфического клиента - читателя, являющегося поклонником научной фантастики, принимающего и одобряющего футуристические образы и события ее сюжета; поведенческая нетривиальность, образная инновационность и фантастичность участников дискурса - протагонистов и героев научно-фантастических произведений как продуктов вымысла агентов дискурса; семиотически ирреальная среда коммуникации героев дискурса; ирреальность складывающейся концептосферы дискурса, элементы которой векторно ориентированы на отдаленную временну́ю перспективу (будущее); инновационность вербальных и невербальных кластеров знаков, формирующих предметную, образную и ценностную составляющие концептов дискурса; фикциональность каналов, режимов и тональности интеракции участников научно-фантасти- ческого дискурса; инновационность жанров интеракции героев дискурса.

Лингвосемиотическая креативность как когнитивная категория выступает операциональной сущностью, которая дает возможность уточнить семиотический статус научно-фантастического дискурса среди прочих видов и типов дискурсов; выявить онтологические функции данного типа дискурса, поскольку первоочередной функцией креативного знака является обеспечение нетривиальности той коммуникативной среды, в которую он попадает и в которой обустраивается (продолжает свое существование и функционирование); детерминировать содержание концептосферы, вовлекаемой в данный тип дискурса; уточнить репертуар хронотопических знаков, вовлеченных в научно-фантастический дискурс; определить и описать состав участников научно-фантастического дискурса; с семиотических позиций проанализировать цели и ценности научно-фантастического дискурса; изучить тактики и стратегии участников научно-фантастического дискурса.

\section{СПИСОК ЛИТЕРАТУРЫ}

1. Базилевич, В. Б. Языковая игра как форма проявления лингвистической креативности / В. Б. Базилевич // Филологические науки. Вопросы теории и практики. -2015. - № 8 (50), ч. III. - С. 20-22.

2. Бутакова, Е. С. Лингвистическая креативность в томской эргонимии / Е. С. Бутакова // Вестник Томского государственного педагогического университета. - 2013. - № 3 (131). - С. 146-152.

3. Галичкина, Е. Н. Компьютерная коммуникация: лингвистический статус, знаковые средства, жанровое пространство / Е. Н. Галичкина. - Волгоград : Парадигма, 2012. $-360 \mathrm{c}$.

4. Галкина, А. В. Овладение лингвистической креативностью в контексте овладения иностранным языком / А. В. Галкина // Вестник Тамбовского государственного университета. Гуманитарные науки. -2011. - № 10 (102). - С. 158-164.

5. Гилфорд, Дж. Психология мышления / Дж. Гилфорд / под ред. А. М. Матюшкина. - М. : Прогресс, 1965. $-525 \mathrm{c}$.

6. Дементьев, В. В. Непрямая коммуникация и ее жанры / В. В. Дементьев / под ред. В. Е. Гольдина. - Саратов : Изд-во Сарат. ун-та, 2000. - 248 с.

7. Зыкова, И. В. Фразеологическая креативность в ракурсе изучения дискурса / И. В. Зыкова // Dyskurs: aspekty lingwistyczne, semiotyczne i 
komunikacyjne / pod redakcją Aleksandra Kiklewicza i Iriny Uchwanowej-Szmygowej. - Olsztyn : Widawnitstwo Uniwersytetu Warmińsko-Mazurskiego, 2015. - S. 157-167.

8. Иняшкин, С. Г. Лингводискурсивные особенности американской научной фантастики середины XX в. / С. Г. Иняшкин // Общество - Язык Культура: актуальные проблемы взаимодействия в XXI веке : тез. докл. Шестой Междунар. науч.практ. конф., МИЛ, 7 дек. 2013 г. - М. : МИЛ, 2013. C. 118-123.

9. Касперова, Л. Т. О природе творчества / Л. Т. Касперова // Актуальные проблемы стилистики. -2015. - № 1. - С. 134-141.

10. Копнина, Г. А. Стилистика креатива и эколингвистика: точки соприкосновения / Г. А. Копнина, А. П. Сковородников // Филологические науки. Вопросы теории и практики. -2014. - № 8 (38), ч. I. C. 101-104.

11. Олянич, А. В. Презентационная теория дискурса / А. В. Олянич. - Волгоград : Парадигма, 2004. $-507 \mathrm{c}$.

12. Стасива, Г. Д. Русский научно-фантастический дискурс XX в. как лингвориторический конструкт / Г. Д. Стасива // Гуманитарные науки: исследования и методика преподавания в высшей школе : материалы 6-й Всерос. науч.-метод. конф. Сочи : РИО СГУТиКД, 2010. - С. 295-301.

13. Тюленева, Т. В. Формирование лингвистической креативности студентов неязыковых специальностей / Т. В. Тюленева // Гуманитарные исследования. -2014 . - № 3 (51). - С. 52-57.

14. Фещенко, В. В. Семиотика творчества и лингвистика креативности / В. В. Фещенко // Общественные науки и современность. -2008 . - № 6. C. $143-150$.

15. Фещенко, В. В. Язык как творчество и творчество в языке: к истории лингвистической идеи / В. В. Фещенко // Критика и семиотика. - 2012. Вып. 17. - С. 84-94.

16. Холодная, М. А. Психология интеллекта. Парадоксы исследования / М. А. Холодная. - СПб. : Питер, 2002. - 368 c.

17. Щербакова, Е. Е. Феномен «лингвистическая креативность» в современной психолого-педагогической науке / Е. Е. Щербакова, Е. В. Левичева // Вестник Нижегородского государственного технического университета. Серия «Управление в социальных системах. Коммуникативные технологии». -2012 . - № 4. - С. 93-101.

18. Amabile, T. M. Social psychology of creativity: a consensual assessment technique / T. M. Amabile // Personal \& Social Psychology. 1982. - Vol. 43. - P. 997-1013.

19. Barron, F., Harrington, D. Creativity, intelligence and personality / F. Barron, D. Harrington
// Annual Review of Psychology. - 1981. - Vol. 32. P. 439-476.

20. Mednick, S. A. The associative basis of the creative process / S. A. Mednick // Psychological Review. - 1962. - Vol. 69. - № 2. - P. 220-232.

\section{REFERENCES}

1. Bazilevich V.B. Yazykovaya igra kak forma proyavleniya lingvisticheskoy kreativnosti [Language Game as a Form of Linguistic Creativity]. Filologicheskie nauki. Voprosy teorii i praktiki, 2015, no. 8 (50), part 3, pp. 20-22.

2. Butakova E.S. Lingvisticheskaya kreativnost $\mathrm{v}$ tomskoy ergonimii [Linguistic Creativity in Tomsk Ergonymy]. Vestnik Vestnik Tomskogo gosudarstvennogo pedagogicheskogo universiteta, 2013, no. 3 (131), pp. 146-152.

3. Galichkina E.N. Kompyuternaya kommunikatsiya: lingvisticheskiy status, znakovye sredstva, zhanrovoe prostranstvo [Computer Communication: Linguistic Status, Symbolic Means, Genre Space]. Volgograd, Paradigma Publ., 2012. 360 p.

4. Galkina A.V. Ovladenie lingvisticheskoy kreativnostyu $\mathrm{v}$ kontekste ovladeniya inostrannym yazykom [Managing the Linguistic Creativity in the Context of Mastering a Foreign Language]. Vestnik Tambovskogo universiteta. Gumanitarnye nauki, 2011, no. 10 (102), pp. 158-164.

5. Gilford Dzh. Psikhologiya myshleniya [Psychology of Mind]. Moscow, Progress Publ., 1965. $525 \mathrm{p}$.

6. Dementyev V.V. Nepryamaya kommunikatsiya i ee zhanry [Indirect Communication and Its Genres]. Saratov, Izd-vo Sarat. un-ta, 2000. 248 p.

7. Zykova I.V. Frazeologicheskaya kreativnost v rakurse izucheniya diskursa [Phraseological Creativity from the Viewpoint of Discourse Studies]. Kiklewicz A., Uchwanowej-Szmygowej I., eds. Dyskurs: aspekty lingwistyczne, semiotyczne $i$ komunikacyjne [Discourse: Linguistic, Semiotic and Communicative Aspects]. Olsztyn, Widawnitstwo Uniwersytetu Warmińsko-Mazurskiego Publ., 2015, pp. 157-167.

8. Inyashkin S.G. Lingvodiskursivnye osobennosti amerikanskoy nauchnoy fantastiki seredinyXX v. [Lingua-Discursive Features of American Science Fiction in the mid 20th Century]. ObshchestvoYazyk - Kultura: aktualnye problemy vzaimodeystviya $v X X I$ veke: tez. dokl. Shestoy Mezhdunar. nauch.-prakt. konf., MIL, 7 dek. 2013 g. [Language - Society - Culture: Urgent Problems of Interaction in the 21st Century. Abstracts of the Sixth International Scientific-Practical Conference, MIL, December 7, 2013]. Moscow, MIL Publ., 2013,pp. 118-123. 
9. Kasperova L.T. O prirode tvorchestva [On the Nature of Creativity]. Aktualnye problemy stilistiki, 2015, no. 1, pp. 134-141.

10. Kopnina G.A., Skovorodnikov A.P. Stilistika kreativa i ekolingvistika: tochki soprikosnoveniya [Stylistics of Creativity and Eco-Linguistics: Points of Juxtaposition]. Filologicheskie nauki. Voprosy teorii i praktiki, 2014, no. 8 (38), part 1, pp. 101-104.

11. Olyanich A.V. Prezentatsionnaya teoriya diskursa [Presentation Theory of Discourse]. Volgograd, Paradigma Publ., 2004. 507 p.

12. Stasiva G.D. Russkiy nauchnofantasticheskiy diskurs XX v. kak lingvoritoricheskiy konstrukt [Russian Science Fiction Discourse of the 20th Century as a Lingua-Rhetorical Construct]. Gumanitarnye nauki: issledovaniya i metodika prepodavaniya $v$ vysshey shkole: materialy 6-y Vseros. nauch.-metod. konf. [Humanities: Research and Teaching Methods in Higher Education: Proceedings of the 6th All-Russian Scientific and Methodical Conference]. Sochi, RIO SGUTiKD Publ., 2010, pp. 295-301.

13. Tyuleneva T.V. Formirovanie lingvisticheskoy kreativnosti studentov neyazykovykh spetsialnostey [Forming of Linguistic Creativity in Students of Nonlingual Specialties]. Gumanitarnye issledovaniya, 2014, no. 3 (51), pp. 52-57.

14. Feshhenko V.V. Semiotika tvorchestva i lingvistika kreativnosti [Semiotics of Creativity and
Linguistics of Creativity]. Obshchestvennye nauki $i$ sovremennost, 2008, no. 6, pp. 143-150.

15. Feshhenko V.V. Yazyk kak tvorchestvo i tvorchestvo $\mathrm{v}$ yazyke: $\mathrm{k}$ istorii lingvisticheskoy idei [Language as Creativity and Creativity in Language: to the History of a Linguistic Idea]. Kritika i semiotika, 2012, iss. 17, pp. 84-94.

16. Kholodnaya M.A. Psikhologiya intellekta. Paradoksy issledovaniya [Psychology of Intellect. Paradoxes of Research]. Saint Petersburg, Piter Publ., $2002.368 \mathrm{p}$.

17. Shcherbakova E.E., Levicheva E.V. Fenomen «lingvisticheskaya kreativnost» v sovremennoy psikhologo-pedagogicheskoy nauke [The Phenomenon of "Linguistic Creativity" in Modern Psychology and Pedagogy]. Vestnik Nizhegorodskogo gosudarstvennogo tekhnicheskogo universiteta. Seriya "Upravlenie v sotsialnykh sistemakh. Kommunikativnye tekhnologii», 2012, iss. 4, pp. 93-101.

18. Amabile T.M. Social psychology of creativity: a consensual assessment technique. Personal \& Social Psychology, 1982, vol. 43, pp. 997-1013.

19. Barron F., Harrington D. Creativity, intelligence and personality. Annual Review of Psychology, 1981, vol. 32, pp. 439-476.

20. Mednick S.A. The associative basis of the creative process. Psychological Review, 1962, vol. 69, no. 2, pp. 220-232.

\section{Information About the Authors}

Andrey V. Olyanich, Doctor of Sciences (Philology), Professor, Department of Foreign Languages, Volgograd State Agrarian University, Prosp. Universitetsky, 26, 400002 Volgograd, Russian Federation, aolyanitch@mail.ru.

Lyubov M. Rylshchikova, Assistant Professor, Department of Foreign Languages, Volgograd State Agrarian University, Prosp. Universitetsky, 26, 400002 Volgograd, Russian Federation, rylshchikova.lubov@mail.ru.

\section{Информация об авторах}

Андрей Владимирович Олянич, доктор филологических наук, профессор кафедры иностранных языков, Волгоградский государственный аграрный университет, просп. Университетский, 26, 400002 г. Волгоград, Российская Федерация, aolyanitch@mail.ru.

Любовь Михайловна Рыльщикова, старший преподаватель кафедры иностранных языков, Волгоградский государственный аграрный университет, просп. Университетский, 26, 400002 г. Волгоград, Российская Федерация, rylshchikova.lubov@mail.ru. 